\title{
ТВЕРДЕ ТІЛО
}

\section{$\mathrm{A}_{1 g}$-МОДА В Нg-1201 ЯК ІНДИКАТОР $\mathrm{N} \rightarrow \mathrm{S}$ ПЕРЕХОДУ \\ Я. ДОВГИй}

УДК 535.33; 537.312; 538.945

(c) 2011
Львівський національний університет ім. Івана Франка

(Вул. Кирила і Мефоділ, 8, Львів 79005; e-mail: dovgy@physics. wups. lviv. uа)
На основі аналізу структури і температурних змін фононних спектрів $\mathrm{HgBa}_{2} \mathrm{CuO}_{4+y}(\mathrm{Hg}-1201)$ вперше визначено константу електрон-фононної взаємодії $g$ і показано, що $\mathrm{Hg}-\mathrm{BTHП} є$ надпровідниками з сильним зв'язком. У фононному спектрі $\mathrm{HgBa}_{2} \mathrm{CuO}_{4+y}$ виявлено ділянку частот поблизу 60,4 меВ, що має ознаки "м'якої моди”. Основний парціальний внесок у функцію густини фононних станів у даній ділянці спектра дають коливання атомів $\mathrm{O}(2)$.

Той факт, що ртутновмісні високотемпературні надпровідники характеризуються високими баричними коефіцієнтами $\beta=d T_{c} / d P$, свідчить про те, що локальні деформації гратки можуть тут відігравати більшу роль, ніж у багатьох інших ВТНП [1]. Тому детальні дослідження динаміки гратки $\mathrm{Hg}$-ВТНП стали предметом особливої уваги експериментаторів. 3 цією метою, крім традиційних оптико-спектральних досліджень фононних спектрів, найчастіше застосовують методи рентгеноабсорбційної спектроскопії та нейтронного розсіювання.

У даній роботі вперше визначено константу електрон-фононної взаємодії високотемпературного надпровідника $\mathrm{HgBa}_{2} \mathrm{CuO}_{4+y}(\mathrm{Hg}-1201)$.

Автори [2] вивчили тонку структуру рентгеноабсорбційних спектрів (XAFS-спектрів) $\mathrm{HgBa}_{2} \mathrm{CuO}_{4+y}$ $\left(T_{c}=96 \mathrm{~K}\right)$ на предмет виявлення динамічних кореляцій (або антикореляцій) на зв'язках $\mathrm{Cu}-\mathrm{O}(2)$ та $\mathrm{Ba}-\mathrm{O}(2)$ (див. рис. 1). За аналізом цієї структури показано, що при $T=80 \mathrm{~K}$ взаємні зміщення атомів $\mathrm{Cu}$ та аксіальних атомів $\mathrm{O}(2)$, а також атомів Ва та атомів $\mathrm{O}(2)$ антикорельовані. Це означає, що у виразі для середньоквадратичного відхилення атомів $a$ і $b$

$\sigma_{a b}^{2}=\sigma_{a}^{2}-\sigma_{b}^{2}-2 \sigma_{a} \sigma_{b} \Phi$ параметр кореляції $\Phi$ є від'ємною величиною $(\Phi<0)$ Випадок $\Phi=1$ відповідає сильній кореляції сусідніх атомів, а випадок $\Phi=0$ - некорельованій динаміці більш віддалених атомів.

Чим зумовлена можливість антикореляції на зв'язках $\mathrm{Cu}-\mathrm{O}(2)$ та $\mathrm{Ba}-\mathrm{O}(2)$ ? Ймовірно, вона зумовлена тим, що положення атома $\mathrm{O}(2)$ може бути різним залежно від того, чи суміжна позиція $\mathrm{O}(3)$ виявляється зайнятою, чи ні. Дійсно, дослідження спектрів комбінаційного розсіювання $\mathrm{HgBa}_{2} \mathrm{CuO}_{4+y}$ показали, що $\mathrm{A}_{1 g}$-мода має дві складові, і це зумовлюється особливістю коливань $\mathrm{O}(2)$. Основний пік $\mathrm{A}_{1 g}$-дублета відповідає $592 \mathrm{~cm}^{-1}$, а менш інтенсивний $-570 \mathrm{~cm}^{-1}$ [3].

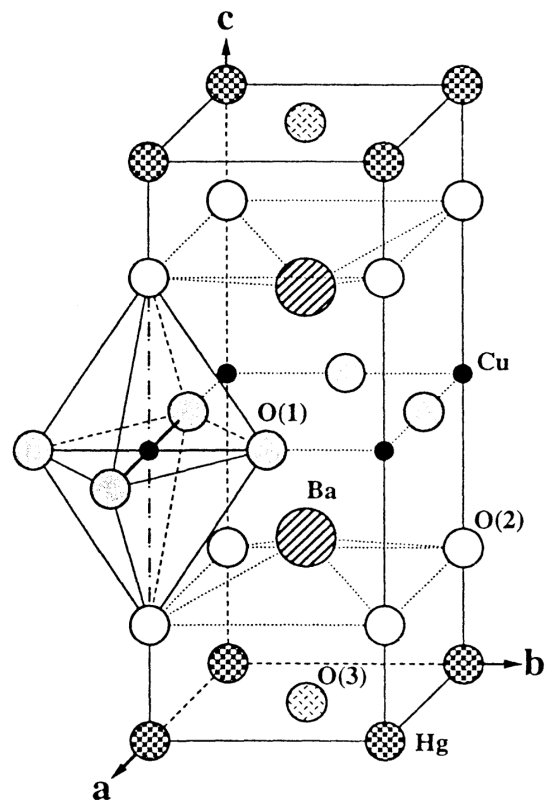

Рис. 1. Кристалічна структура $\mathrm{HgBa}_{2} \mathrm{CuO}_{4+y}$ (Hg-1201). Вакансіям кисню відповідають положення $\mathrm{O}(3)$ 


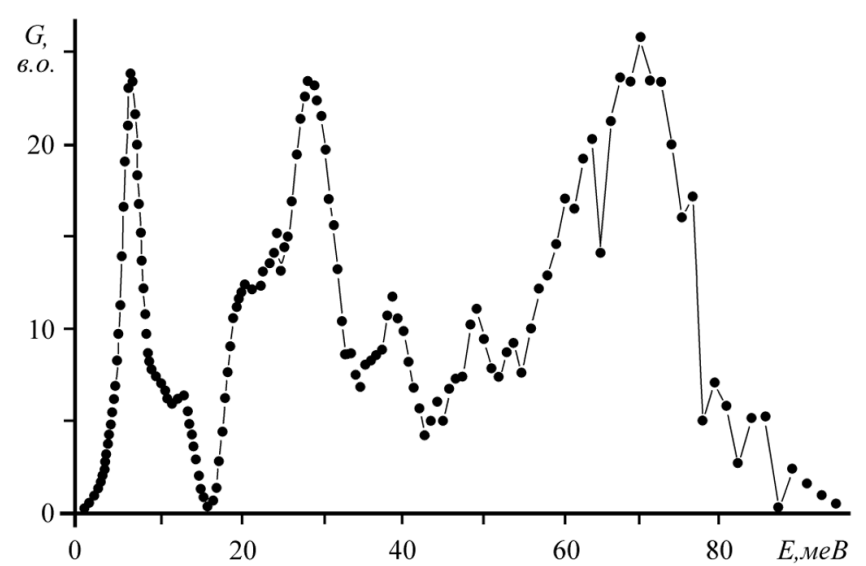

Рис. 2. Функція фононної густини станів $\mathrm{HgBa}_{2} \mathrm{CuO}_{4+y}$ при кімнатній температурі

Отже, маємо два можливих положення атомів $\mathrm{O}(2)$, що зумовлюються локальним перерозподілом заряду. Даний фактор може стосуватися й механізму спарювання носіїв у $\mathrm{CuO}_{2}$-шарах. До речі, вказаний $\mathrm{A}_{1 g^{-}}$ дублет, як виявилося у [4], особливо чутливий до тиcку.

На основі досліджень методом непружного розсіювання низькоенергетичних нейтронів вдалося отримати функцію узагальненої густини станів $\mathrm{HgBa}_{2} \mathrm{CuO}_{4+y}$ (рис. 2) [5]. Вимірювання проводили на реакторі в Греноблі. Використовували монокінетичний пучок нейтронів з енергією 17,4 меВ. Інтенсивність розсіювання реєстрували в кутовому діапазоні $23^{\circ}<\alpha<99^{\circ}$, що при відомій методиці обробки результатів забезпечувало охоплення значного об'єму імпульсного простору та отримання надійних значень густини фононних станів $G(E)$.

Високоенергетична ділянка у структурі спектра $G(E)$ може бути пов'язана з кисневими модами подібно до $\mathrm{YBa}_{2} \mathrm{Cu}_{3} \mathrm{O}_{7-\delta}$ та Вi-ВТНП [6]. Зокрема основні піки 73,4 меВ (592 $\left.\mathrm{cm}^{-1}\right)$ та 20,8 меВ (168 $\left.\mathrm{cm}^{-1}\right)$ відповідають $\mathrm{A}_{1 g^{-}}$та $\mathrm{E}_{g}$-модам коливного спектра $\mathrm{O}(2)$.

На рис. 3 наведено зіставлення експериментального спектра $G(E)$ з результатами модельних розрахунків. Силові константи та інші параметри для обчислень було взято з огляду [7], в якому проаналізовано великий масив експериментальних даних щодо надпровідних оксидних купратів.

Як видно з рис. 3, експериментальні та розрахункові спектри $G(E)$ якісно узгоджуються. Розбіжність у високоенергетичній ділянці пояснюється впливом дефектності реальних керамічних зразків. Чіткі піки поблизу $28 \mathrm{меB}\left(226 \mathrm{~cm}^{-1}\right)$ і $70 \mathrm{meB}\left(565 \mathrm{~cm}^{-1}\right)$ відповідають $T O$ - та $L O$-модам вершинного кисню,

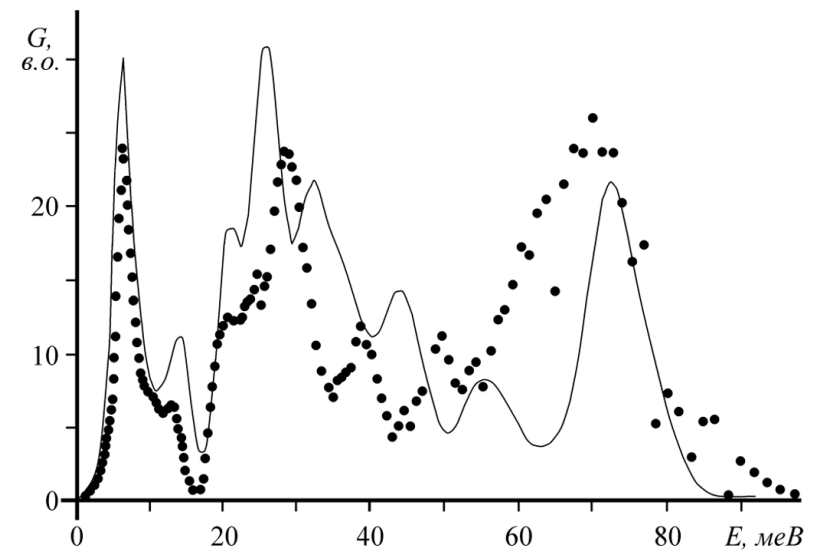

Рис. 3. Порівняння експериментального спектра (точки) з результатами модельних розрахунків (суцільна лінія)

причому ці моди є характерними для $\mathrm{Hg}$-ВТНП $з$ різною кількістю $\mathrm{CuO}_{2}$-шарів в елементарній комірці.

Як відомо [8, 9], у $\mathrm{YBa}_{2} \mathrm{Cu}_{3} \mathrm{O}_{7-\delta}$ фононна мода симетрії $\mathrm{B}_{1 g}\left(335 \mathrm{~cm}^{-1}\right)$ має властивості “м'якої моди" і вона пов'язана 3 надпровідною щілиною $2 \Delta$. Чи існує подібна мода в Нg-ВТНП? У зв'язку з цим становить значний інтерес відстежування температурної поведінки фононних спектрів цих матеріалів.

На рис. 4 показано температурні зміни функції $G(E)$, одержані методом непружного розсіювання нейтронів на зразках $\mathrm{HgBa}_{2} \mathrm{CuO}_{4+y}$ [5]. Як видно, поблизу 60,4 меВ спостерігаються суттєві зміни спектра при охолодженні зразка до температури переходу у надпровідний стан. В інших ділянках спектр не зазнає помітних температурних змін.

Таким чином, мода 60,4 меВ в $\mathrm{HgBa}_{2} \mathrm{CuO}_{4+y}$ виявляє певні ознаки “м'якої моди”. Температурні зміни вказують, що в цьому діапазоні частот найбільший внесок в $G(E)$ дають коливання $\mathrm{O}(2)$ і що дана мода може пов'язуватися 3 переходом із нормальної у надпровідну фазу. Дане припущення підтверджується у роботі [10], де автори спостерігали аналогічні температурні зміни при дослідженні раманівських спектрів $\mathrm{Hg}$-ВТНП. М'яка мода коливань $\mathrm{Cu}-\mathrm{O}(2)$ була виявлена також авторами [11] при дослідженні оптимально допованих зразків $\mathrm{HgBa}_{2} \mathrm{CuO}_{4+y}$.

За аналогією до $\mathrm{YBa}_{2} \mathrm{Cu}_{3} \mathrm{O}_{7-\delta}$ ми допускаємо, що енергетична щілина $\mathrm{HgBa}_{2} \mathrm{CuO}_{4+y}$

$2 \Delta \cong 60,4 \mathrm{меB}$,

звідки маємо

$2 \Delta /\left(k T_{c}\right) \approx 7,2$. 
Як відомо, за теорією БКШ співвідношення $2 \Delta /\left(k T_{c}\right)=3,52$, що вдвічі менше від (3). Така разюча невідповідність теорії БКШ, перш за все, може вказувати, що у сполуках Hg-ВТНП маємо справу зі значно сильнішим електрон-фононним зв'язком, ніж це передбачається в теорії БКШ.

Як відомо, відомості щодо симетрії та форми (в імпульсному просторі) щілини в енергетичному спектрі на поверхні Фермі надпровідника є вельми важливими для аналізу моделей спарювання.

В Hg-1201, як і в інших оксидних купратах, надпровідність зумовлена куперівським спарюванням $d$ типу, так що енергетична щілина може мати нулі на поверхні Фермі. Однак відсутність детальних даних щодо топології поверхні Фермі поки що не дозволяє судити про характер анізотропії $d$-спарювання в цьому матеріалі.

Температурна поведінка "індикаторної" смуги свідчить про те, що електрон-фононна взаємодія є суттєвою у механізмі спарювання. Не можна виключати 3 розгляду також механізму, пов'язаного зі спіновими флуктуаціями, адже достеменно встановлено, що оксидні купрати відносяться до систем із сильними електронними кореляціями. Варті уваги й інші моделі [12]. У зв'язку $з$ цим однозначна інтерпретація природи енергетичної щілини в $\mathrm{Hg}-1201$ є проблематичною ${ }^{1}$.

У даній роботі зроблено спробу оцінки величини константи електрон-фононної взаємодії $g$ у рамках моделі сильного зв'язку. Нами використано апроксимаційну формулу Аллена-Дайнса [14]:

$T_{c} \cong\left(\frac{f_{1} f_{2}}{1,20} \omega_{a} \frac{\hbar}{k}\right) \exp \left[-\frac{1,04(1+g)}{g-\mu^{*}(1+0,62 g)}\right]$,

де

$f_{1}=\left[1+\left(g / a_{1}\right)^{3 / 2}\right]^{1 / 3}$

$f_{2}=1-\frac{g^{2}\left(1-\omega_{0} / \omega_{a}\right)}{g^{2}+a_{2}^{2}}$

$a_{1}=2,46\left(1+3,8 \mu^{*}\right)$,

$a_{2}=1,82\left(1+6,3 \mu^{*}\right) \omega_{0} / \omega_{a}$,

\footnotetext{
1 Зауважимо, що для систем з частковою діелектризацією електронного спектра можливе виникнення також щілини моттовського типу [13].
}

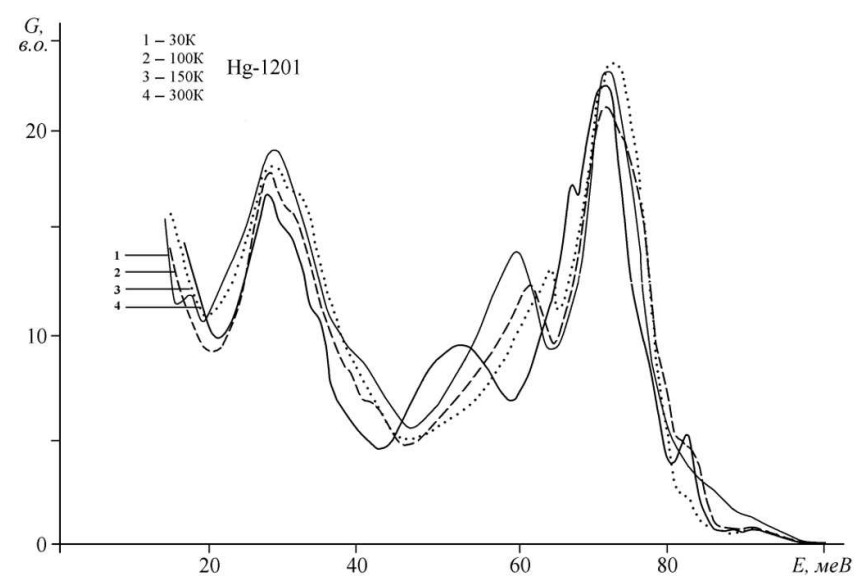

Рис. 4. Температурні зміни фононних мод $\mathrm{HgBa}_{2} \mathrm{CuO}_{4+y}$

$\mu^{*}=\frac{\mu}{1+\mu \ln \left(E_{\mathrm{F}} /\left(\hbar \omega_{\mathrm{D}}\right)\right)}$,

$\mu$ - параметр, що характеризує кулонівське відштовхування носї̈, $\omega_{\mathrm{D}}$ - дебаєвська частота, $k$ - стала Больцмана.

3 аналізу функції $G(E)$, зображеної на рис. 2, одержали

$\hbar \omega_{0} \cong 28,5 \mathrm{MeB}$.

Якщо взяти до уваги, що

$\hbar \omega_{a} \cong 2 \Delta$

а параметр модифікованого кулонівського потенціалу згідно з [15], дорівнює

$\mu^{*} \cong 0,13$

то після громіздких обчислень одержуємо

$g \cong 2,0$.

Таким чином, можна стверджувати, що ртутновмісні високотемпературні надпровідники характеризуються сильним електрон-фононним зв'язком. Пошук закономірностей зміни параметра $g$ залежно від кількості $\mathrm{CuO}_{2}$-шарів в елементарній комірці буде предметом наших подальших досліджень.

1. Я.О. Довгий, УФЖ 46, 585 (2001).

2. C.H. Booth, F. Bridges, E.D. Bauer, G.G. Li, J.B. Boyce, T. Claeson, C.W. Chu, and Q. Xiong, Phys. Rev. B 52, 15745 (1995).

3. H.G. Lee, H.S. Shin, I.S. Yang, J.J. Yu, and N.H. Hur, Physica C 233, 35 (1994). 
4. I.-S. Yang, H.-S. Shin, and H.-G.Lee, Phys. Rev. B 51, 644 (1995).

5. B. Renker, H. Schober, and F. Gompf, J. Low. Temp. Phys. 105, 843 (1996).

6. B. Renker, F. Gompf, D. Ewert, P. Adelmann, H. Schmidt, E. Gering, and H. Mutka, Z. Phys. B 77, 65 (1989).

7. S.L. Chaplot, W. Reichardt, L. Pintschovius, and N. Pyka, Phys. Rev. B 52, 7230 (1995).

8. Физические свойства высокотемпературных сверхпроводников Под ред. Д.Гинзбурга (Мир, Москва, 1990).

9. R. Zeyher and G. Zwicknagl, Z. Phys. B 78, 175 (1990).

10. M.C. Krantz, C. Thomsen, Hj. Mattausch, and M. Cardona, Phys. Rev. B 50, 1165 (1994).

11. H. Uchiyama, A.Q.R. Baron, S. Tsutsui, Y. Tanaka, W.-Z. Hu, A. Yamamoto, S. Tajima, and Y. Endoh, Phys. Rev. Lett. 92, 197005 (2004).

12. Я.О. Довгий, Чарівне явище надпровідність (Євросвіт, Львів, 2000).

13. A.M. Gabovich, A.I. Voitenko, and M. Ausloos, Phys. Rep. 367, 583 (2002).

14. P.B. Allen and R.C. Dynes, Phys. Rev. B 12, 905 (1975).

15. H.B. Radousky, T. Jarlborg, G.S. Knapp, and A.J. Freeman, Phys. Rev. B 26, 1208 (1982).

Одержано 08.06.11
$\mathrm{A}_{1 g}$-МОДА В Нg-1201 КАК ИНДИКАТОР $\mathrm{N} \rightarrow \mathrm{S}$ ПЕРЕХОДА

Я. Довгий

Р е з ю м е

На основе анализа структуры и температурных изменений фононних спектров $\mathrm{HgBa}_{2} \mathrm{CuO}_{4+y}$ ( $\left.\mathrm{Hg}-1201\right)$ впервые определено константу электрон-фононного взаимодействия $g$ и показано, что Нg-ВТНП являются сверхпроводниками с сильной связью. В фононном спектре $\mathrm{HgBa}_{2} \mathrm{CuO}_{4+y}$ выявлено участок частот вблизи 60,4 мэВ с признаками "мягкой моды". Основной парциальный вклад в функцию плотности фононных состояний на данном участке спектра дают колебания атомов $\mathrm{O}(2)$.

THE $\mathrm{A}_{1 g}$ MODE IN THE Hg-1201 PHONON SPECTRUM AS AN INDICATOR OF $\mathrm{N} \rightarrow \mathrm{S}$ TRANSITION

Ya. Dovhyj

Ivan Franko National University of L'viv

(8, Kyrylo i Mefodiy Str., Lviv 79005, Ukraine

e-mail:dovgy@physics.wups.lviv.ua)

$\mathrm{S} \mathrm{u} \mathrm{m} \mathrm{m} \mathrm{a} \mathrm{r} \mathrm{y}$

By analyzing the structure of and the temperature changes in $\mathrm{HgBa}_{2} \mathrm{CuO}_{4+y}$ phonon spectra, the electron-phonon coupling constant $g$ has been determined for the first time. It is shown that this compound is a superconductor with strong coupling. A frequency interval around $60.4 \mathrm{meV}$ in the $\mathrm{HgBa}_{2} \mathrm{CuO}_{4+y}$ phonon spectrum, which may be classed as a "soft mode", is revealed. The dominant partial contribution to the density of phonon states in that spectral range is found to be given by $\mathrm{O}(2)$ atomic vibrations. 